\title{
A Highly Active Polymer-Supported Catalyst for Asymmetric Robinson Annulations in Continuous Flow
}

\author{
Santiago Cañellas, ${ }^{\dagger, \ddagger}$ Carles Ayats, ${ }^{\dagger, \ddagger}$ Andrea H. Henseler,${ }^{\dagger}$ Miquel A. Pericàs ${ }^{\star, \dagger, \S}$ \\ ${ }^{\dagger}$ Institute of Chemical Research of Catalonia (ICIQ), The Barcelona Institute of Science and Technology, Avda. \\ Països Catalans 16, E-43007 Tarragona, Spain \\ ${ }^{\S}$ Departament de Química Inorgànica i Orgànica, Universitat de Barcelona, 08028 Barcelona, Spain
}

\begin{abstract}
The preparation through Robinson annulation of enantiopure building blocks with both academic and industrial relevance, such as the Wieland-Miescher and Hajos-Parrish ketones, has suffered from important drawbacks, such as the need of high catalyst loading or extremely long reaction times. Here we report a heterogeneized organocatalyst based on Luo's diamine for the fast and broad-scope enantioselective Robinson annulation reaction. The polystyrene-supported diamine 19a enables the high-yield, highly enantioselective preparation of a wide scope of chiral bicyclic enones under mild conditions, with reaction times as short as 60 minutes (batch) or residence times of 10 minutes (flow). In contrast with its homogeneous counterpart 19b, the catalytic resin 19a experiences a notable increase in catalytic activity with temperature in 2-MeTHF (a ten-fold decrease in reaction times without erosion in enantioselectivity is observed from room temperature to $55^{\circ} \mathrm{C}$ ). The scope of the transformation in batch has been illustrated with 14 examples, including examples only reported in poorly enantioenriched (22n) or in racemic form (22k). Enantiopure 22k has been used as starting material for a straightforward formal synthesis of the antibiotic and antifeedant sesquiterpene (-)-isovelleral (24). The heterogeneized catalyst 19a admits extended recycling (10 cycles) and has been used to develop the first asymmetric Robinson annulations in continuous flow. The potential of the flow process is illustrated by the large scale preparation of the Wieland-Miescher ketone $(65 \mathrm{mmol}$ in $24 \mathrm{~h}$ operation, TON of 117) and by a sequential flow experiment leading to a library of eight enantioenriched diketone compounds.
\end{abstract}

KEYWORDS : Robinson annulation, Continuous flow, Heterogeneized catalysts, Wieland-Miescher ketone, Hajos-Parrish ketone

The Hajos-Parrish-Eder-Sauer-Wiechert (H-P-E-S-W) reaction to access chiral bicyclic enones, via an intramolecular aldol reaction, is one of the most well-known organocatalytic processes. Reported in 1971 by two independent industrial research groups, this L-proline-catalyzed process enables the isolation of enantioenriched Wieland-Miescher (W$M, 1$ ) and Hajos-Parrish (H-P, 2) ketones (Figure 1). While high enantioselectivity was achieved for the H-P ketone (2), the W-M ketone (1) was obtained with moderate enantioselectivity. In both cases, prolonged reaction times were required.

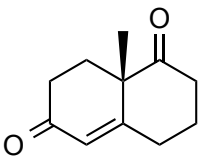

W-M ketone, 1<smiles>C[C@]12CCC(=O)C=C1CCC2=O</smiles>

H-P ketone, 2

Figure 1. Wieland-Miescher ketone (W-M ketone, 1) and Hajos-Parrish ketone (H-P ketone, 2).

Enantioenriched W-M and H-P ketones provide access to a broad variety of sesquiterpenoids, diterpenoids and steroids. Biological activities of these compounds include antimicrobial, anticancer, antiviral and antineurodegenerative effects. For these reasons, since 2000, following the seminal work by List and Barbas on the use of proline as a catalyst for enantioselective aldol reaction, there has been a resurgent interest in achieving more efficient routes for these catalytic processes. As a result, several new organocatalysts have emerged for the synthesis of these bicyclic enones. ${ }^{-\ldots m o n g}$ them, most structures are based on chiral amines for promoting the reaction through enamine activation mode.

For instance, proline-catalyzed "one-pot" procedures," cyclic-amino acid $(1 R, 2 S)$-cispentacin,' amino acids and short $\alpha / \beta$-peptides," bimorpholine derivatives," prolinamide," prolinethiomide," 1,2-cyclohexanediamine derivatives," binaphthylprolinamides," and chiral vicinal-diamines" have been developed. Recently, a BINOL-derived phosphoric acid" was 
also reported as organocatalyst to perform this transformation through hydrogen-bonding activation mode (For some examples, see Figure 2).

Most of the aforementioned organocatalysts were able to perform the synthesis of W-M and H-P ketones, however important drawbacks such as high catalyst loading, limited scope or very long reaction times (from 10 hours to 7 days) are present in all cases." Importantly, the chiral vicinal-diamine developed by Luo"wis promoted Robinson annulation reactions very efficiently, leading to a series of chiral bicyclic enones in very high yield and stereoselectivity in notably short reaction times (12-24 hours).

Practical applications of homogeneous asymmetric catalysis in industrial processes are limited due to issues associated with high cost of chiral catalysts. Catalyst immobilization onto solid supports can be a feasible approach as catalysts can be isolated from the reaction mixture by simple filtration, and the recovered catalyst can be reused repeatedly during consecutive catalytic cycles. Additionally, heterogeneized catalysts can be applied in continuous flow processes with the advantage of not being co-eluted during the process." Moreover, the alleged limitations of immobilized metal catalysts, ${ }^{\infty}$ mostly centered on metal leaching, should not apply with covalently bonded organocatalysts.

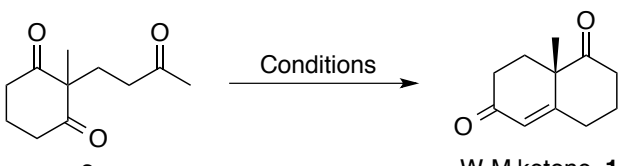

3

W-M ketone, 1

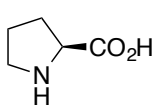

$35 \mathrm{~mol} \%, 3.7$ days $49 \%$ yield, $76 \%$ ee

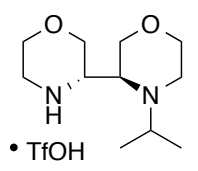

5

5 mol\%, 4 days $60 \%$ yield, $95 \%$ ee

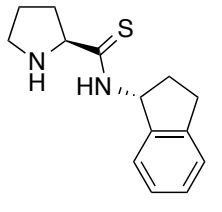

6

$5 \mathrm{~mol} \%, 24$ days $99 \%$ yield, $86 \%$ ee

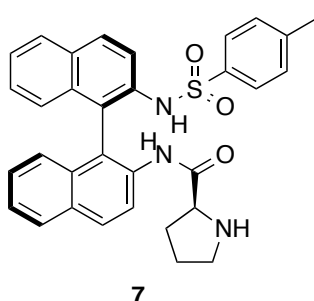

2 mol\%, 7 days $94 \%$ yield, $94 \%$ ee

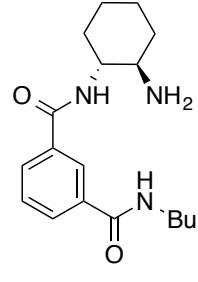

8

$10 \mathrm{~mol} \%, 16$ hours $85 \%$ yield, $95 \%$ ee

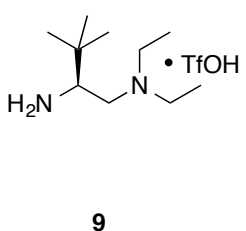

$10 \mathrm{~mol} \%, 10$ hours $73 \%$ yield, $92 \%$ ee

Figure 2. Selected organocatalysts for the synthesis of W-M ketone through enamine activation mode.

Considering the advantages of heterogenized catalysts, and the high volume of reports regarding new organocatalysts for enantioselective formation of W-M and H-P ketone derivatives, been reported dealing with the development of immobilized catalysts applicable to this transformation. In addition, all of them require extremely prolonged reaction times, and either moderate results or non-recyclability of the catalysts is recorded."

In response to these unmet demands, that could greatly facilitate the preparation of important enantiopure building blocks (e.g., the W-M and H-P ketones), herein we report the preparation of a highly-active polymer-supported chiral vicinal-diamine catalyst for the asymmetric preparation of bicyclic diketones through the Robinson protocol in batch and flow. This is, to the best of our knowledge, the first implementation of this important transformation in continuous flow. Through its application, the large-scale synthesis of the W-M ketone, as well as the sequential preparation of a library of W-M and H-P type diketones derivatives, are implemented in a highly productive, single-pass continuous flow process. 


\section{RESULTS AND DISCUSSION}

Inspired by the success of Luo's report for using the triflate ammonium salt of chiral vicinal-diamine 9," we considered the opportunity of developing an immobilized version of this catalyst that could add to the properties of $\mathbf{9}$ the possibility of extended recycling and reuse.

Our design principle (Figure 3) involved modification of the diethylamino fragment in order to introduce a handle that could allow immobilization with minimal perturbation of the enantiodiscriminating transition state in the key aldol reaction. After extensive experimentation, we identified the polymer-supported derivative 19 a as a most promising catalyst candidate for the synthesis of $\mathrm{W}-\mathrm{M}$ and $\mathrm{H}-\mathrm{P}$ ketone derivatives.
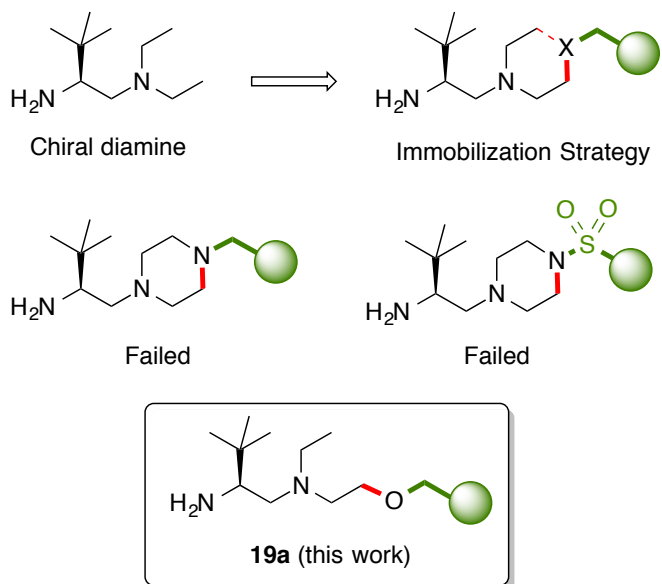

Figure 3. Design principle followed in this study and candidate evolution towards 19a.

The preparation of 19a from L-tert-leucine is shown in Scheme 1. For comparison purposes, the homogeneous analogue $19 \mathrm{~b}$ was also prepared. Starting from commercially available L-tert-leucine 10, reduction with sodium borohydryde in the presence of iodine, ${ }^{2}$ produced an amino-alcohol which was $N$-protected with Boc $\mathrm{O}$ under basic conditions to afford (S)- $N$-Boc tert-leucinol 11 in $89 \%$ yield (2 steps).. Mesylation of the Boc-protected amine 11 and subsequent cyclization with potassium tert-butoxide afforded the desired aziridine 13 in $72 \%$ Yield (2 steps).. Ringopening with the 2-(ethylamino)ethanol 14 led to the desired $N$-Boc amino alcohol 15 (68\% yield), whose structure could be confirmed by X-ray crystallographic analysis." Acid-mediated Boc deprotection of 15 gave rise to aminoalcohol 16 in good yield (95\% yield). Ultimately, 16 could be tethered to microporous polystyrene via nucleophilic substitution of the chlorine atoms of commercially available Merrifield resin $17(1 \%$ DVB, $f=1.55 \mathrm{mmol} / \mathrm{g})$ to afford $19 \mathrm{a}$ with high immobilization yield $(f=0.99 \mathrm{mmol} / \mathrm{g}, f=1.25 \mathrm{mmol} / \mathrm{g}, 79 \%)$. Likewise, the homogeneous catalyst 19b could be prepared in very good yield (95\%) from 16 and benzyl bromide $\mathbf{1 8}$

With heterogeneized catalyst 19a in hand, its use was initially optimized under batch conditions for the formation of W-M ketone 1, from the corresponding triketone 3 (Table 1).
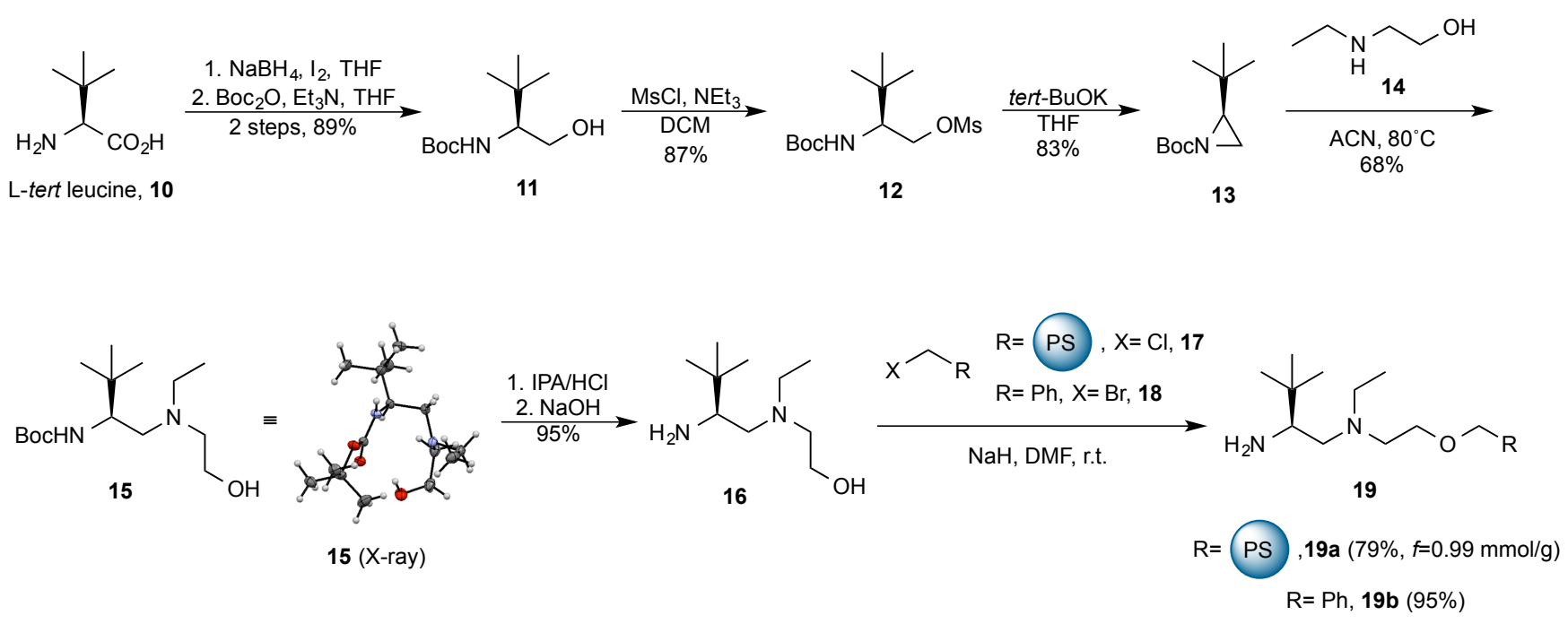

Scheme 1. Synthesis of the PS-Supported catalyst 19a and the homogeneous analogue 19b.

Table 1. Optimization of the reaction conditions for $19 a$. 


Catalyst $19 a(10 \mathrm{~mol} \%)$
solvent, acid, $m-\mathrm{NO}_{2} \mathrm{C}_{6} \mathrm{H}_{4} \mathrm{CO}_{2} \mathrm{H}$

Reactions performed at room temperature in a High-Throughput Experimentation (HTE) facility using triketone 3 (50 $\mu \mathrm{mol})$, catalyst 19a (10 mol\%) and solvent (1M). Reaction time: 12 hours. HPLC yields determined by using naphthalene as internal standard. Determined by HPLC on the crude reaction mixture using a chiral stationary phase. Bench reaction conditions: triketone $3(0.14 \mathrm{mmol})$, catalyst $19 \mathrm{a}(10 \mathrm{~mol} \%)$ and 2-MeTHF $(1 \mathrm{M})$. Temperature: $55^{\circ} \mathrm{C}$ and 1 hour reaction.

Screening of different parameters, such as solvents, acids for the preformation of the ammonium salt of 19a and additives was performed in a High-Throughput Experimentation (HTE) platform (see Table S1 for a more detailed account). The catalytic activity of resin 19a was comparable in all tested solvents, high values of enantiomeric excesses $(>90 \%$ ee) being recorded in all cases (Table 1, entries 1-4). Regarding reactivity, however, reactions performed in DCM were considerably slower than in DMF, DMF: $\mathrm{HO}$ and THF. The catalytic activity also showed a dependence on the pK of the acids used to form the ammonium salt of $19 a$, which is active catalyst. After some experiments with different acids, we selected the strongest acid tested (triflic acid, $10 \mathrm{~mol} \%$ ) as the best option (Table 1, entries 4-8). Furthermore, with the addition of a mild acid such as $m-\mathrm{NOCHCOH}(5 \mathrm{~mol} \%)$ as an additive, better results were recorded in comparison with experiments where an excess of strong acid was used (Table 1, entries 9-10). This enhancement of reactivity can be rationalized by considering acid-facilitated iminium-enamine tautomerization." This observation is consistent with previous reports by Luo."

Observing the good catalytic activity in THF, a greener solvent, 2-MeTHF was also tested. Gratifyingly, similar results were also recorded, therefore future experiments were performed in 2-MeTHF (Table 1, entry 11).

Although high yield and enantiomeric excesses could be achieved under this set of reaction conditions, we sought the possibility of decreasing reaction time by modifying the reaction temperature. To our delight, the reaction was impressively fast at $55^{\circ} \mathrm{C}$, triketone 3 being consumed in just 1 hour with practically no erosion in enantioselectivity (Table 1 , entry 12).

We next examined the possibility of achieving the Wieland-Miescher ketone 1 through Robinson annulation reaction between commercially available diketone 20a and methyl vinyl ketone 21a. By employing the same optimized conditions for triketone 3 as starting material ( $10 \mathrm{~mol} \%$ of $19 \mathrm{a}, 10 \mathrm{~mol} \% \mathrm{TfOH}, 5 \mathrm{~mol} \% \mathrm{~m}-\mathrm{NO} \mathrm{CHCOH}_{2} 55^{\circ} \mathrm{C}$ ), full conversion of diketone 20a was also achieved in just 1 hour without decrease in enatioselectivity (Table S4). To the best of our knowledge, the present procedure shortens by one order of magnitude the reaction times of the best previous procedures (more than 10 hours required)" for the preparation of the Wieland-Miescher ketone 1 while keeping excellent levels of enantiocontrol (more than $90 \%$ ee).

As aforementioned, reaction temperature was a crucial parameter in this highly optimized Robinson annulation procedure mediated by 19a. To understand this temperature effect, some comparative experiments were performed under the same conditions with the homogeneous catalysts $\mathbf{1 9 b}$ and $\mathbf{9}$. Since solvent is needed when using PS-Supported catalysts, these reactions were also performed in 2-MeTHF. It is important to note that reactions in 2-MeTHF mediated by $19 \mathrm{~b}$ and 9 were remarkably slower than those performed under the standard neat conditions (Table 2, entries 2$5,6-11)$. A solvent dependence observed with catalyst 9 was already reported in the literature." All three catalysts, 19a, 19b and 9 had same behavior when reactions were performed at room temperature (Table 2, entries 2, 8 and 13); however, important deviations in activity were detected when temperature changed. Surprisingly, the previously ob- 
served enhancement in the reactivity at higher temperatures for 19a was not as pronounced for the homogeneous variants $19 \mathrm{~b}$ and 9 . For instance, when the reaction is performed at $60^{\circ} \mathrm{C}$ for 12 hours, very good yield and enantioselectivity was obtained using PS-Supported catalyst 19a (Table 2, entry 12). In contrast, homogeneous catalysts 9 and 19b achieved inferior results in 72 hours at the same temperature under neat conditions (Table 2, entries 1 and 6). For reactions in 2-MeTHF, the reactivity of the homogeneous catalysts was even lower (Table 2, entries 5 and 7). The enhanced reactivity of the resin 19a when increasing temperature likely reflects a beneficial effect of the non-polar polystyrene environment on the activity of the supported catalysts. While this effect could be somewhat masked by mass transfer limitations at room temperature, it becomes fully operational at $55-60{ }^{\circ} \mathrm{C}$. Similar beneficial effects have been previously noted and could be reminiscent of those found in the active sites of enzymes." The polymeric matrices have been shown to very efficiently increase the local concentration of both substrates within the confined reaction pocket present on them" and, in this case, higher temperatures could activate the molecules inside the hydrophobic pockets much more efficiently than in solution.

Encouraged by these results, we next turned our attention to explore the catalytic scope of 19a in Robinson annulation reactions leading, among other, to $\mathrm{W}-\mathrm{M}$ and $\mathrm{H}-\mathrm{P}$ ketone derivatives (Scheme 2).

Table 2. Screening conditions comparing homo- and heterogeneous catalysts for Robinson annulation reaction.
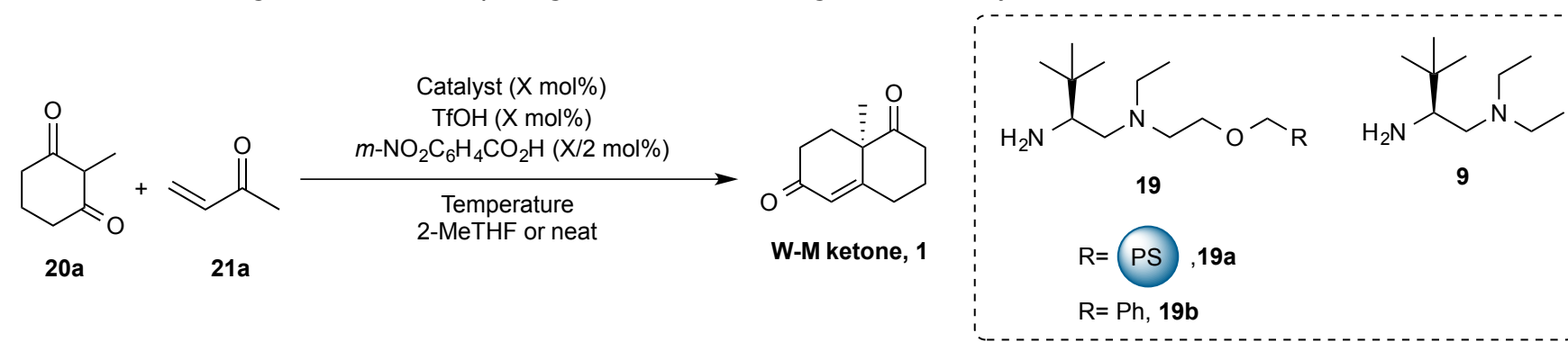

$\begin{array}{cccc}\text { Entry } & \text { Catalyst }(\mathrm{mol} \%) & \text { Time }(\mathrm{h}) & \text { Temperature }\left({ }^{\circ} \mathrm{C}\right) \\ 1 & \mathbf{9}(2 \mathrm{~mol} \%) & 72 & 60 \\ 2 & \mathbf{9}(10 \mathrm{~mol} \%) & 10 & \text { r.t. } \\ 3 & \mathbf{9}(10 \mathrm{~mol} \%) & 24 & \text { r.t. } \\ 4 & \mathbf{9}(10 \mathrm{~mol} \%) & 6 & 55 \\ 5 & \mathbf{9}(10 \mathrm{~mol} \%) & 6 & 55 \\ 6 & \mathbf{1 9 b}(2 \mathrm{~mol} \%) & 72 & 60 \\ 7 & \mathbf{1 9 b}(2 \mathrm{~mol} \%) & 96 & 60 \\ 8 & \mathbf{1 9 b}(10 \mathrm{~mol} \%) & 16 & \text { r.t. } \\ 9 & \mathbf{1 9 b}(10 \mathrm{~mol} \%) & 48 & \text { r.t. } \\ 10 & \mathbf{1 9 b}(10 \mathrm{~mol} \%) & 1 & 55 \\ 11 & \mathbf{1 9 b}(10 \mathrm{~mol} \%) & 2 & 55 \\ 12 & \mathbf{1 9 a}(2 \mathrm{~mol} \%) & 12 & 60 \\ 13 & \mathbf{1 9 a}(10 \mathrm{~mol} \%) & 10 & \text { r.t. } \\ 14 & \mathbf{1 9 a}(10 \mathrm{~mol} \%) & 1 & 55\end{array}$

$\begin{array}{ccc}\text { Solvent } & \text { Yield (\%) } & \text { ee (\%) } \\ \text { neat } & 87 & 90 \\ \text { neat } & 73 & 92 \\ \text { 2-MeTHF } & \text { traces } & \text { nd } \\ \text { neat } & 50 & 90 \\ \text { 2-MeTHF } & 28 & 89 \\ \text { neat } & 72 & 89 \\ \text { 2-MeTHF } & 45 & 89 \\ \text { neat } & 80 & 94 \\ \text { 2-MeTHF } & 42 & 92 \\ \text { neat } & 65 & 90 \\ \text { 2-MeTHF } & 62 & 90 \\ \text { 2-MeTHF } & 93 & 90 \\ \text { 2-MeTHF } & 88 & 93 \\ \text { 2-MeTHF } & 88 & 91\end{array}$

${ }^{a}$ Reaction conditions: 2-methyl-1,3-cyclohexanedione 20a $(0.27 \mathrm{mmol})$, methyl vinyl ketone 21a $(0.32 \mathrm{mmol})$, catalyst $(2$ or 10 mol\%), TfOH (2 or $10 \mathrm{~mol} \%), m-\mathrm{NO}_{2} \mathrm{C}_{6} \mathrm{H}_{4} \mathrm{CO}_{2} \mathrm{H}$ (1 or $\left.5 \mathrm{~mol} \%\right), 2-\mathrm{MeTHF}\left(0.27 \mathrm{~mL}\right.$ ) or neat. ${ }^{b}$ Isolated yields. ${ }^{c}$ Determined by performing HPLC using a chiral stationary phase of the crude mixture. ${ }^{d} 2$-Methyl-1,3-cyclohexanedione $20 \mathrm{a}(7.9 \mathrm{mmol})$ and methyl vinyl ketone 21a $(9.48 \mathrm{mmol})$ were used. ${ }^{e} 2$-Methyl-1,3-cyclohexanedione $20 \mathrm{a}(0.5 \mathrm{mmol})$ and methyl vinyl ketone $21 \mathrm{a}(0.6 \mathrm{mmol})$ were used. ${ }^{2}$-Methyl-1,3-cyclohexanedione 20a $(3.96 \mathrm{mmol})$ and methyl vinyl ketone $21 \mathrm{a}(4.76 \mathrm{mmol})$ were used. 

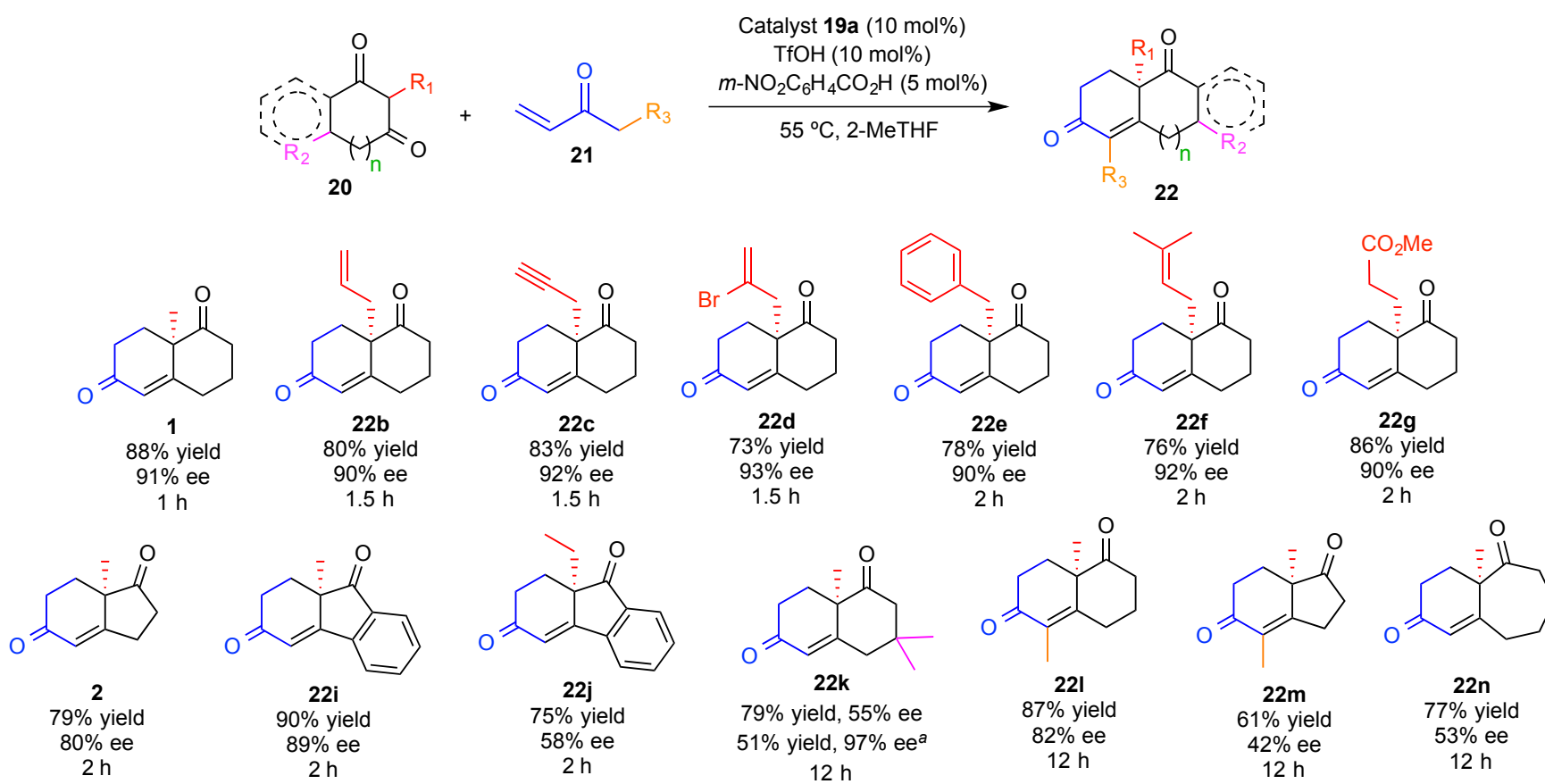

Scheme 2. Robinson annulation reaction scope. Isolated yields. After recrystallization.

Bicyclic diketones of the [4.4.0] type (W-M type) bearing a variety of substituents at carbon $8 \mathrm{a}$ in the ring junction (1, 22b-g), were prepared in short reaction times (1-2 hours) and very high enantiomeric excesses (up to 93\%). The method also allowed to achieve H-P ketone 2 in only 2 hours reaction time with yield and enantioselectivity similar to those reported in the literature. However, it is important to note that all previously reported procedures required prolonged reaction times (1-7 days). ." Moreover, two H-P ketone derivatives bearing a condensed benzo ring (22i and 22j) were also successfully prepared with very good results. The fluorene-based skeleton present in these compounds is of interest since it is present in many bioactive compounds such as agents for the treatment of brain edema or selective Estrogen Receptor $\beta$-subtype (ER $\beta$ ) agonists." Interestingly, substrate 22i bearing a methyl group at position 8a has been obtained with a higher level of enantiocontrol compared to those reported by the analogous homogeneous catalyst $9(65 \%$ ee)." Furthermore, compound 22j has been prepared for the first time using an enamine activation mode." We also investigated the formation of C5-substituted bicyclic diketones $\mathbf{2 2}$ and $\mathbf{2 2 m}$, previously prepared through amino acid promoted Robinson annulation." Interestingly, reactions catalyzed by 19 a were considerably faster, leading to $\mathbf{2 2}$ in high yield and enantioselectivity. Not unexpectedly, results were more modest for 22m. Resin 19a also catalyzed the formation of the enantioenriched [5.4.0] bicyclic diketone 22n. This unusual bicyclic core has been found in several natural products with attractive biological activities such as guanacastepenes and heptemerones." It should be noted that previous attempts at accessing enantioenriched 22n using organocatalysis were unsuccessful." The synthesis of this compound has been reported very recently using lipases as a biocatalyst, however very poor values of enantiomeric excess $(8 \%$ ee) were achieved and extremely prolonged reaction times ( 8 days) were needed. In our case, the 7-membered ring bicyclic enone $22 \mathrm{n}$ was obtained in good yield $(77 \%)$ and moderate enantiomeric excess $(53 \%)$ in a rather short reaction time $(12 \mathrm{~h})$.

Interestingly, the enantioselective synthesis of 22k, bearing a gem-dimethyl group at position-3 of the W-M ketone skeleton, has remained elusive in the literature. Several articles reported that attempts to obtain 22k in optically active form following previously reported procedures developed for the asymmetric synthesis of the Wieland-Miescher ketone using chiral organocatalysts were unsuccessful." In our hands, resin 19a catalyzed the formation of compound 22k in good yield and excellent enantioselectivity after crystallization. Importantly, ketone 22k has been shown to be an interesting intermediate for the total synthesis of several natural products as furanether B and (+)-isovelleral 24. Since previously reported organocatalysts failed to form enantioenriched $\mathbf{2 2 k}$, all reported routes towards synthesis of furanether B and (+)-isovelleral involved racemic synthesis of $\mathbf{2 2 k}$ and subsequent enzymatic resolution of one advanced intermediate of $\mathbf{2 2 k}$ by Candida Rugosa lipase (CRL). For instance, eight synthetic steps were needed to get protected alcohol 23, a key intermediate for the synthesis of the natural antibiotic and antifeedant sesquiterpene from Basidiomycetes (+)-isovelleral $\mathbf{2 4}$, in only moderate enantiomeric purity $(83 \%$ ee).* The use of $\mathbf{1 9 a}$ for the direct preparation of enantioenriched frameworks like 22k may provide many opportunities for the synthesis of attractive natural products which have remained elusive due to the low reactivity of the gem-dimethyl diketone 20k in Robinson annulation. To illustrate this potential, we have successfully carried out a short formal synthesis of the equally active and less mutagenic enantiomer (-)-isovelleral 24, using asymmetric Robinson annulation promoted by PS-Supported catalyst 19a as the key step (Scheme 3). 

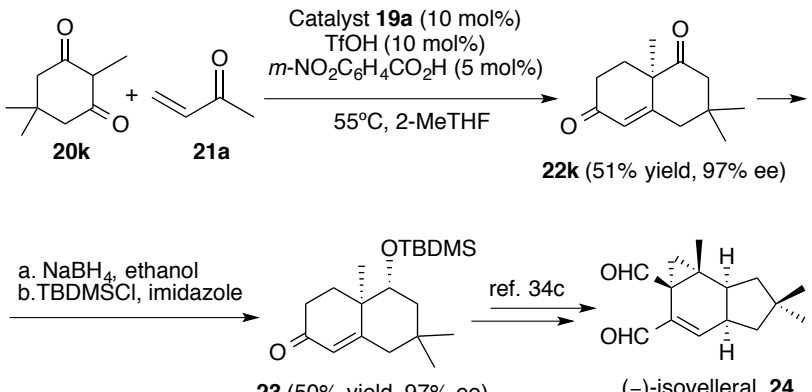

Scheme 3. Formal synthesis of (-)-isovelleral using the PS-Supported catalyst 19a.

Chemo- and diastereoselective reduction of the non-conjugated ketone moiety in 22k with sodium borohydride and subsequent alcohol protection with tert-butyldimethylsilyl chloride gave rise to $\mathbf{2 3}$ in $50 \%$ overall yield and very high enantiomeric purity $(97 \%$ ee).." In this manner, only three steps are required to obtain diastereo- and enantiomerically pure intermediate $\mathbf{2 3}$ from commercially available starting materials in contrast to the much longer (8 step) and less enantioselective synthesis reported in the literature."

One of the most important advantages offered by supported catalysts is the possibility to recover them by simple filtration and reuse them in a new catalytic cycle." In order to test the robustness of the PS-Supported catalyst 19a, recycling experiments in the model Robinson annulation reaction for the synthesis of W-M ketone $\mathbf{1}$ was performed. Initially, experiments were done using 2-methyl-1,3-cyclohexadione 20a and methyl vinyl ketone 21a (Scheme 2), however a significant decrease in the reactivity along cycles was observed and resin 19a could only be recycled for 3 times with moderate results." To understand the reason for catalyst deactivation, control experiments with the homogeneous catalyst $19 \mathrm{~b}$ were performed. In one of these tests, homogeneous catalyst 19b was kept in contact with methyl vinyl ketone under the optimized reaction conditions. Careful analysis of the reaction mixture revealed the formation of mono and dialkylated derivatives of 19b resulting from the aza-Michael addition to methyl vinyl ketone 21a. We considered this process as the most probable origin of the deactivation of 19a. If this was the case, the deactivation could be avoided by simply performing the reactions from the meso triketone 3 . Indeed, much better recyclability of resin 19a was observed, although a slight decrease in the reactivity was detected as the recycling progressed. By slightly adapting reaction conditions, very high yields and enantiomeric excesses were achieved in 10 consecutive reaction cycles by just increasing 15 minutes the reaction time from one to the next cycle (Table 3).

The great catalytic activity showed by the PS-Supported catalyst 19a convert it into a suitable candidate for a continuous flow processing. The achievement of this goal, that has not even been considered before due to the long reaction times and high catalyst loadings normally associated to Robinson annulation, would exert an enormous impact on the potential use of this important methodology for production purposes. We accordingly set up our efforts to convert the enantioselective Robinson annulation mediated by 19a into a continuous flow process.

Table 3. Recyclability experiments of the PS-Supported catalyst 19a.

$\begin{array}{ccccc}\begin{array}{c}\text { Cy- } \\ \text { cle }\end{array} & \text { Time (h) } & \text { Conv. (\%) } & \text { Yield (\%) } & \text { ee (\%). } \\ 1 & 1 & 95 & 89 & 90 \\ 2 & 1.25 & 95 & 90 & 90 \\ 3 & 1.5 & 95 & 89 & 91 \\ 4 & 1.75 & 96 & 91 & 90 \\ 5 & 2 & 95 & 89 & 92 \\ 6 & 2.25 & 95 & 89 & 90 \\ 7 & 2.5 & 94 & 88 & 91 \\ 8 & 2.75 & 93 & 86 & 90 \\ 9 & 3 & 92 & 83 & 90 \\ 10 & 3.25 & 91 & 80 & 92\end{array}$

Reactions performed using triketone $3(0.27 \mathrm{mmol})$, catalyst $19 \mathrm{a}(10 \mathrm{~mol} \%)$, TfOH $(10 \mathrm{~mol} \%), m-\mathrm{NOCHCOH}(5$ mol\%) and 2-MeTHF as solvent (1M). 'Determined by H-NMR spectroscopy. Isolated yield. After purification.

Due to solubility issues, the solvent used during the continuous flow experiments was DMF." Since the starting materials of the process (20a and 21a) do not react in solution in presence of $m-\mathrm{NO} \mathrm{CHCO}_{2} \mathrm{H}$, and one single catalyst is used for the whole transformation (Michael plus desimetrizing aldol reaction), we first tried to circulate a solution of diketone 20a, methyl vinyl ketone $\mathbf{2 1 a}$ and co-catalyst $m-\mathrm{NOCHCOH}$ in DMF through a cartridge containing the preswollen catalyst 19a. Not unexpectedly, the PS-Supported catalyst 19a was also deactivated in continuous flow due 
to the aza-Michael side reaction discussed above. To avoid this problem, we decided to take advantage from PSsupported base catalysts to allow a simple, batch preparation of $\mathbf{3}$ in solution through a process involving minimal manipulation of the reaction crude. In this manner the deletereous methyl vinyl ketone would be completely consumed before the reactants would enter the reactor containing the catalytic resin 19a. Some commercially available PSSupported bases, such as PS-DIPEA, PS-piperazinomethyl and PS-DBU (Table S7), were tested with this purpose. PS-Supported DBU 25 turned out to be the catalyst of choice for this transformation, leading at 2 mol\% loading to full conversion of an equimolar mixture of commercially available diketone 20a and methyl vinyl ketone 21a in only $4 \mathrm{~h}$ at $60{ }^{\circ} \mathrm{C}$. Very clean DMF solutions of Michael adduct $\mathbf{3}$ were obtained in this manner. A simple filtration for removal of particles in suspension was required for its use in the continuous flow process. Then, crude mixture was directly injected together with $m-\mathrm{NO}$

The simple continuous flow set-up used for the continuous flow experiments is shown in Figure 4. A preformed DMF solution of 3 (see above) was combined with $m-\mathrm{NOCHCOH}(5 \mathrm{~mol} \%)$ and pumped through a size-adjustable MPLC jacketed glass column packed with $0.8 \mathrm{~g}(0.56 \mathrm{mmol}, f=0.7 \mathrm{mmol} \cdot \mathrm{g})$ of 19a. A back-pressure regulator at $1.3 \mathrm{bar}$ was connected at the reactor outlet, and the catalytic reactor was heated to $60^{\circ} \mathrm{C}$ for operation. The continuous flow process was monitored by recording $\mathrm{H}-\mathrm{NMR}$ spectra of aliquots of the eluting solution every hour. Although conversion showed a slight decrease along a $24 \mathrm{~h}$ experiment, we were able to keep conversion high through according modification of flow rate (Table S8). To our delight, this unprecedented enantioselective continuous flow process allowed the preparation of $11.7 \mathrm{~g}(65.5 \mathrm{mmol})$ of enantioenriched $\mathrm{W}-\mathrm{M}$ ketone 1 in 24 hours of operation, corresponding to an impressive TON of 117.

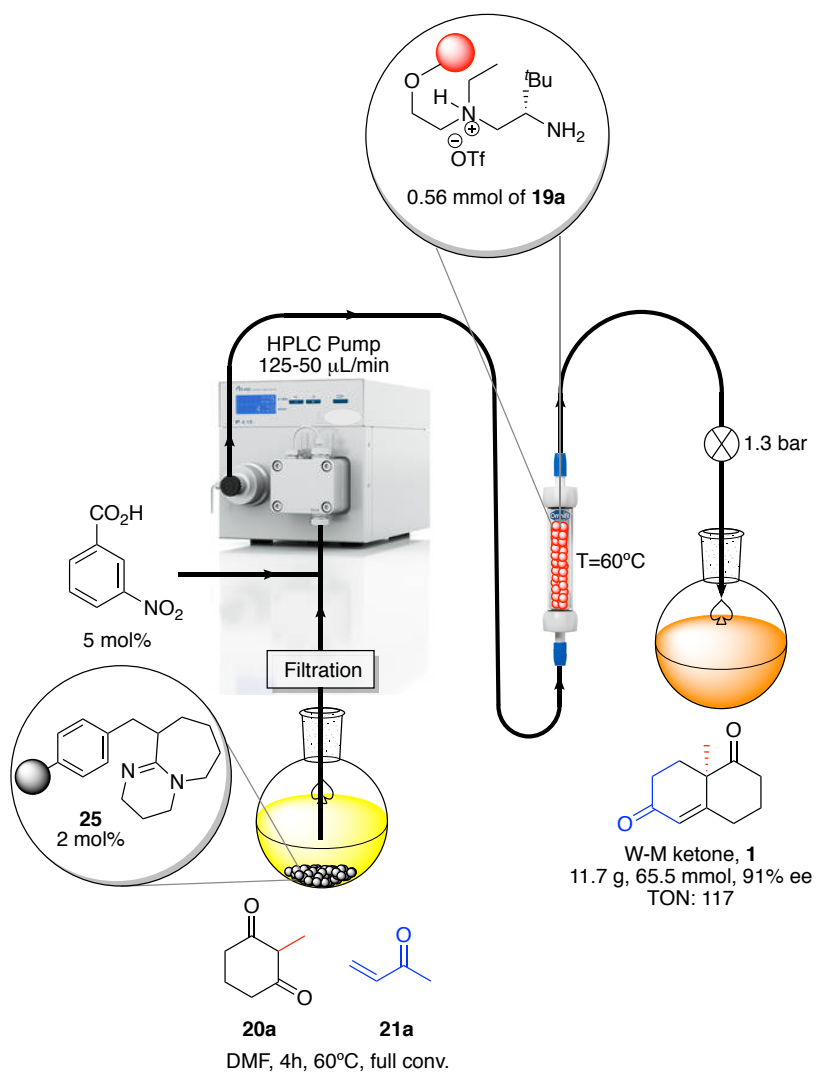

Figure 4. Set-up for the continuous flow Robinson annulation catalyzed for 19a.

Catalytic asymmetric flow processes based on immobilized catalysts are of particular interest in diversity oriented synthesis, since a single set-up operation can be easily performed to prepare a library of enantiopure compounds in a sequential manner." Taking advantage of the versatility of the PS-Supported vicinal diamine 19a, a diverse library of enantioenriched Robinson annulation products was sequentially prepared using the set-up described above (Figure 4). As for the preparation of the W-M ketone, the starting materials were reacted in the presence of PS-DBU 25, and the crude DMF solutions of meso triketones were filtered and directly injected into the catalytic reactor in combination with $m-\mathrm{NO} C \mathrm{HCOH}$. Each individual solution was circulated through the system for 30 minutes at $100 \mu \mathrm{L} \cdot \mathrm{min}$ (residence time: 10 minutes). For the avoidance of cross-contamination, the column was washed with DMF for 1 hour between the preparation of two consecutive products. Hence, eight enantioenriched bicyclic enones $(\mathrm{H}-\mathrm{P}$ ketone $\mathbf{2}$, 22i, 22g, 22e, 22d, 22c, 22b and W-M ketone 1) were sequentially prepared (Table 4).

The diversity oriented continuous flow process was successfully carried out with very high productivities (TOF $=6.7$ $9.3 \mathrm{mmol} \cdot \mathrm{mmol}_{\ldots} \cdot \mathrm{h}$ ) and afforded a library of Robinson annulation products with the same level of enantioselectivity 
recorded in batch (Scheme 2). From a practical perspective, the robustness of the resin is further verified by the fact that, after 7 consecutive runs with different substrates, the W-M ketone 1 was prepared again (entry 8) with similar results to those recorded in the $24 \mathrm{~h}$ experiment in flow. Thus, resin 19a could still be used with many more substrates as one would expect from a pre-packed catalyst cartridge.

Table 4. Diversity oriented asymmetric Robinson annulation in continuous flow.

Entry Product Yield (\%) TOF ee (\%)

1 .

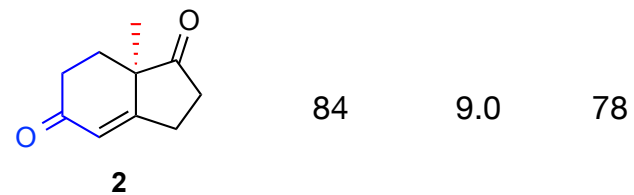

2<smiles>C[C@]12CCC(=O)C=C1c1ccccc1C2=O</smiles>

22i

3.<smiles>CC(=O)CCC12CCC(=O)C=C1CCCC2=O</smiles>

22g

4<smiles>O=Cc1ccccc1</smiles><smiles>C=C1CCCC2=CC(=O)CC[C@]12C</smiles>

5<smiles>C=C(Br)[14CH2]O[14CH2]</smiles><smiles>O=C1C=C2CCCC3=CCC[C@@H]3CC2C1</smiles>

79

62

63

8<smiles>C[C@]12CCC(=O)C=C1CCCC2=O</smiles>

6.892

$8.7 \quad 89$

$9.3 \quad 90$

$9.0 \quad 92$

$8.4 \quad 93$

$6.7 \quad 94$

8.6 91

TOF in $\mathrm{mmol} \cdot \mathrm{mmol} \cdot \mathrm{h}$. Treated with PS-SOH to complete the dehydration step (2 mol\%, 4h, $\left.100^{\circ} \mathrm{C}\right)$. Determined by HPLC analysis of the reaction crude using a chiral stationary phase. 


\section{CONCLUSION}

In summary, we have developed a PS-supported chiral vicinal diamine conceptually derived from Luo's catalyst that combines the selectivity performance of the homogeneous model with unique characteristics derived from its polymeric nature. Very high catalytic activity at convenient reaction temperatures and the possibility of extended recycling convert 19a in the catalyst of choice for asymmetric Robinson annulations. Besides allowing the preparation of widely used building blocks, such as the enantioenriched $\mathrm{W}-\mathrm{M}$ or the H-P ketones in very short reaction times (1-2 hours), 19a also allows the convenient preparation of interesting and previously elusive enantioenriched bicyclic enones. In particular, adduct 22k allows the straightforward preparation of an advanced intermediate in the synthesis of $(-)$ isovelleral with important step economy over previous approaches. The remarkable catalytic activity/enantioselectivity/recyclability profile of 19 a has eventually led to the development of the first Robinson annulation in continuous flow. Its application in the multigram synthesis of the enantioenriched W-M ketone or in the sequential preparation of a diverse library of Robinson annulated products show the potential of simple, pre-packed columns of resin $19 a$ as re-usable, multipurpose reactors for this academically and industrially relevant transformation in flow.

\section{ASSOCIATED CONTENT}

\section{Supporting Information}

Experimental procedures and spectral data (PDF)

Crystallographic data (CIF)

\section{AUTHOR INFORMATION}

\section{Corresponding Author}

*E-mail: mapericas@iciq.es.

\section{Author Contributions}

¥ S. C. and C. A. contributed equally to this work.

\section{Notes}

The authors declare no competing financial interest.

\section{ACKNOWLEDGMENT}

Financial support from MINECO (grant CTQ2015-69136-R (MINECO/FEDER)) and ICIQ Foundation is gratefully acknowledged. We also thank MINECO for support through the Severo Ochoa Excellence Accreditation 2014-2018 (SEV-2013-0319) and the CELLEX Foundation for funding the CELLEX-ICIQ high throughput experimentation (HTE) platform. SC thanks MINECO for a Severo Ochoa FPI fellowship, CA thanks the CELLEX Foundation for a post-doctoral contract, and AHH thanks the MECD for a FPU fellowship. We are grateful to the ICIQ X-ray diffraction unit for the X-ray structure of $\mathbf{1 5}$ and to Dr. Xisco Caldentey for the assistance with the HTE experiments.

\section{REFERENCES}

(1) For reviews, see: (a) List, B. Acc. Chem. Res. 2004, 37, 548-557. (b) Notz, W.; Tanaka, F.; Barbas, C. F. III Acc. Chem. Res. 2004, 37, 580-591. (c) Volla, C. M. R.; Atodiresei, I.; Rueping, M. Chem. Rev. 2014, 114, 2390-2431. (d) Urabe, D.; Asaba, T.; Inoue, M. Chem. Rev. 2015, 115, 9207-9231. (e) Afewerki, S.; Córdova, A. Chem. Rev. 2016, 116, 13512-13570.

(2) (a) Eder, U.; Sauer, G.; Wiechert, R. Angew. Chem. 1971, 83, 492-493. (b) Hajos, Z. G.; Parrish, D. R. J. Org. Chem. 1973, 38, 3239-3243. (c) Hajos, Z. G.; Parrish, D. R. J. Org. Chem. 1974, 39, 1615-1621. (d) Micheli, R. A.; Hajos, Z. G.; Cohen, N.; Parrish, D. R.; Portland, L. A.; Sciamanna, W.; Scott, M. A.; Wehrli, P. A. J. Org. Chem. 1975, 40, 675-681.

(3) For reviews, see: (a) Bradshaw, B.; Bonjoch, J. Synlett 2012, 23, 337-356 and references herein. (b) Zeng, X.-P.; Cao, Z.-Y.; Wang, Y.-H.; Zhou, F.; Zhou, J. Chem Rev. 2016, 116, 7330-7396 and references herein. For reports on the synthesis of natural products: (c) Ziegler, F. E.; Wallace, O. B. J. Org. Chem. 1995, 60, 3626-3636. (d) Dzierba, C. D.; Zandi, K. S.; Möllers, T.; Shea, K. J. J. Am. Chem. Soc. 1996, 118, 4711-4712. (e) Danishefsky, S. J.; Masters, J. J.; Young, W. B.; Link, J. T.; Snyder, L. B.; Magee, T. V.; Jung, D. K.; Isaacs, R. C. A.; Bornmann, W. G.; Alaimo, C. A.; Coburn, C. A.; Di Grandi, M. J. J. Am. Chem. Soc. 1996, 118, 2843-2859. (f) Stork, G.; West, F.; Lee, H. Y.; Isaacs, R. C. A.; Manabe, S. J. Am. Chem. Soc. 1996, 118, 10660-10661. (g) Lee, H. M.; Nieto-Oberhuber, C.; Shair, M. D. J. Am. Chem. Soc. 2008, 130, 16864-16866.

(4) List, B.; Lerner, R. A.; Barbas, C. F. III J. Am. Chem. Soc. 2000, 122, 2395-2396.

(5) (a) Mukherjee, S.; Yang, J. W.; Hoffmann, S.; List, B. Chem. Rev. 2007, 107, 5471-5569. (b) Trost, B. M.; Brindle, C. S. Chem. Soc. Rev. 2010, 39, 1600-1632.

(6) (a) Rajagopal, D.; Rajagopalan, K.; Swaminathan, S. Tetrahedron: Asymmetry 1996, 7, 2189-2190. (b) Bui, T.; Barbas, C. F. III Tetrahedron Lett. 2000, 42, 6951-6954. (c) Rajagopal, D.; Narayanan, R.; Swaminathan, S. Tetrahedron Lett. 2001, 42, 4887-4890.

(7) Davies, S. G.; Sheppard, R. L.; Smith, A. D.; Thomson, J. E. Chem. Commun. 2005, 3802-3804.

(8) (a) Limbach, M. Tetrahedron Lett. 2006, 47, 3843-3847. (b) Nagamine, T.; Inomata, K.; Endo, Y.; Paquette, L. A. J. Org. Chem. 2007, 72, 123-131. (c) Davies, S. G.; Russell, A. J.; Sheppard, R. L.; Smith, A. D., Thomsom, J. E. Org. Biomol. Chem. 2007, 5, 3190-3200. (d) D’Elia, V.; Zwicknagl, H.; Oliver, R. J. Org. Chem. 2008, 73, 3262-3265. 
(9) Kanger, T.; Kriis, K.; Laars, M.; Kailas, T.; Müürisepp, A.-M.; Pehk, T.; Lopp, M. J. Org. Chem. 2007, 72, 5168-5173.

(10) Zhang, X. M.; Wang, M.; Tu, Y. Q.; Fan, C. A.; Jiang, Y. J.; Zhang, S. Y.; Zhang, F. M. Synlett 2008, 18, 2831-2835.

(11) Almasi, D.; Alonso, D. A.; Nájera, C. Adv. Synth. Catal 2008, 350, 2467-2472.

(12) (a) Fuentes de Arriba, A. L.; Seisdedos, D. G.; Simón, L.; Alcázar, V.; Raposo, C.; Morán, J. R. J. Org. Chem. 2010, 75, 8303-8306. (b) Rubio, O. H.; Fuentes de Arriba, A. L.; Monleón, L. M.; Sanz, F.; Simón, L.; Alcázar, V.; Morán, J. R. Tetrahedron 2015, 71, 1297-1303.

(13) (a) Bradshaw, B.; Etxebarria-Jardi, G.; Bonjoch, J.; Viózquez, S. F.; Guillena, G.; Nájera, C. Adv. Synth. Catal. 2009, 351, 2482-2490. (b) Bradshaw, B.; Etxebarria-Jardi, G.; Bonjoch, J. J. Am. Chem. Soc. 2010, 132, 5966-5967. (c) Bradshaw, B.; Etxebarria-Jardí, G.; Bonjoch, J.; Viózquez, S. F.; Guillena, G.; Nájera, C. Org. Synth. 2011, 88, 330-341.

(14) (a) Zhou, P.; Zhang, L.; Luo, S.; Cheng, J.-P. J. Org. Chem. 2012, 77, 2526-2530. (b) Xu, C.; Zhang, L.; Zhou, P.; Luo, S.; Cheng, J.-P. Synthesis 2013, 45, 1939-1945. (c) Luo, S.; Xu, C.; Zhang, L. Patent CN 10355931A 2014.

(15) For the preparation of 22j mediated by a chiral phosphoric acid, see: Mori, K.; Katoh, T.; Suzuki, T.; Noji, T.; Yamanaka, M.; Akiyama, T. Angew. Chem. Int. Ed. 2009, 48, 9652-9654.

(16) Chiral vicinal diamine developed by Luo's has also been used for many other very highly enantioselective processes. For reviews see: (a) Zhang, L.; Fu, N.; Luo, S. Acc. Chem. Res. 2015, 48, 986-997. (b) Rodriguez, J. Coquerel, Y. ChemCatChem 2015, 7, 1263-1264. For research papers see: (c) Hu, S.; Zhang, L.; Li, J.; Luo, S.; Cheng, J.-P. Eur. J. Org. Chem. 2011, 3347-3352. (d) Xu, C.; Zhang, L.; Luo, S. Angew. Chem. Int. Ed. 2014, 53, 4149-4153. (e) Xu, C.; Zhang, L.; Luo, S. J. Org. Chem. 2014, 79, 11517-11526. (f) Zhu, Y.; Zhang, L.; Luo, S. J. Am. Chem. Soc. 2014, 136, 14642-14645. (g) Wang, D.; Xu, C.; Zhang, L.; Luo, S. Org. Lett. 2015, 17, 576-579. (h) Xu, C.; Zhang, L.; Luo, S. Org. Lett. 2015, 17, 4392-4395. (i) Zhu, Y.; Zhang, L.; Luo, S. J. Am. Chem. Soc. 2016, 138, 3978-3981.

(17) For recent reviews on immobilized catalyst and reagents: (a) Lu, J.; Toy, P. H. Chem. Rev. 2009, 109, 815-838 (b) Zhao, G.; Chai, Z. In Recoverable and Recyclable Catalysts; Benaglia, M., Ed.; Wiley, Chichester, 2009; pp 49-75. (c) Kristensen, T. E.; Hansen, T. Eur. J. Org. Chem. 2010, 3179-3204.

(18) For recent examples, see: (a) Zhao, D.; Ding, K. ACS Catal. 2013, 3, 928-944. (b) Puglisi, A.; Benaglia, M.; Chiroli, V. Green Chem. 2013, 15, 1790-1813. (c) Tsubogo, T.; Ishiwata, T.; Kobayashi, S. Angew. Chem., Int. Ed. 2013, 52, 6590-6604. (d) Pastre, J. C.; Browne, D. L.; Ley, S. V. Chem. Soc. Rev. 2013, 42, 8849-8869. (e) Wiles, C.; Watts, P. Green Chem. 2014, 16, 55-62. (f) Rodríguez-Escrich, C.; Pericàs, M. A. Eur. J. Org. Chem. 2015, 1173-1188. (g) Munirathinam, R.; Huskens, J.; Verboom, W. Adv. Synth. Catal. 2015, 357, 1093-1123. (h) Atodiresei, I.; Vila, C.; Rueping, M. ACS Catal. 2015, 5, 1972-1985. (i) Puglisis, A.; Benaglia, M.; Porta, R.; Coccia, F. Current Organocatalysis 2015, 2, 79-101.

(19) For recent successful examples from our laboratory involving asymmetric continuous flow processes with immobilized catalysts: (a) Sagamanova, I. K.; Rodríguez-Escrich, C.; Molnár, I. G.; Sayalero, S.; Gilmour, R.; Pericàs, M. A. ACS Catal. 2015, 5, 6241-6248. (b) Kasaplar, P.; Ozkal, E.; Rodríguez-Escrich, C.; Pericàs, M. A. Green Chem. 2015, 17, 3122-3129. (c) Izquierdo, J.; Ayats, C.; Henseler, A. H.; Pericàs, M. A. Org. Biomol. Chem. 2015, 13, 4204-4209. (d) Izquierdo, J.; Pericàs, M. A. ACS Catal. 2016, 6, 348-356. (e) Osorio-Planes, L.; Rodríguez-Escrich, C.; Pericàs, M. A. Catal. Sci. Technol. 2016, 6, 4686-4689. (f) Llanes, P.; Sayalero, S.; Rodríguez-Escrich, C.; Pericàs, M. A. Green Chem. 2016, 18, 3507-3512. (g) Clot-Almenara, L.; Rodríguez-Escrich, C.; Osorio-Planes, L.; Pericàs, M. A. ACS Catal. 2016, 6, 7647-7651.

(20) S. Hübner, J. G. de Vries, V. Farina, Adv. Synth. Catal. 2016, 358, 3-25.

(21) For polymer-supported catalysts: (a) Kondo, K.; Yamano, T.; Takemoto, K. Makromol. Chem. 1985, 186, 1781-1785. (b) Pedrosa, R.; Andrés, J. M.; Manzano, R.; Pérez-López, C. Tetrahedron Lett. 2013, 54, 3101-3104. For silica-supported catalysts: (c) Monge-Marcet, A.; Cattoën, X.; Alonso, D. A.; Nájera, C.; Chi Man, M. W.; Pleixats, R. Green Chem. 2012, 14, 1601-1610. (d) Bañón-Caballero, A.; Guillena, G.; Nájera, C.; Faggi, E.; Sebastián, R. M.; Vallribera, A. Tetrahedron 2013, 69, 1307-1315. For PEGsupported catalyst: (e) Benaglia, M.; Cinquini, M.; Cozzi, F.; Puglisi, A.; Celentano, G. Adv. Synth. Catal. 2002, 344, $533-542$.

(22) Krout, M.R.; Mohr, J. T.; Stoltz, B. M. Org. Synth. 2009, 86, 181-193.

(23) Ebner, C.; Pfaltz, A. Tetrahedron 2011, 67, 10287-10290.

(24) Xiao, H.; Chai, Z.; Zhenh, C.-W.; Yang, Y.-Q.; Liu, W.; Zhang, J.-K.; Zhao, G. Angew. Chem, Int. Ed. 2010, 49, 4467-4470.

(25) Giles, P. R.; Rogers-Evans, M.; Soukup, M.; Knight, J. Org. Process Res. Dev. 2003, 7, 22-24.

(26) Weiping, Y.; Junye, X.; Zhining, H.; Hongxiang, W.; Shihua, X.; Xianglan, X.; Fei, C. Patent CN $103364959 A 2014$.

(27) See the Supporting Information for details.

(28) (a) Font, D.; Jimeno, C.; Pericàs, M. A. Org. Lett. 2006, 8, 4653-4655. (b) Font, D.; Sayalero, S.; Bastero, A.; Jimeno, C.; Pericàs, M. A. Org. Lett. 2008, 10, 337-340. (c) Alza, E.; Pericàs, M. A. Adv. Synth. Catal. 2009, 351, 3051-3056.

(29) (a) Cotanda, P.; Lu, A.; Patterson, J. P.; Petzetakis, N.; O’Reilly, R. K. Macromolecules 2012, 45, 2377-2384. (b) Lu, A.; O’Reilly, R. K. Curr. Opin. Biotechnol. 2013, 24, 639-645.

(30) (a) CragoeJr., E. J.; WoltersdorfJr., O. W.; Gould, N. P.; Pietruszkiewicz, A. M.; Ziegler, C.; Sakurai, Y.; Stokker, G. E.; Anderson, P. S.; Bourke, R. S. J. Med. Chem. 1986, 29, 825-841. (b) Wilkening, R. R.; Ratcliffe, R. W.; Fried, A. K.; Meng, D.; Sun, W.; Colwell, L.; Lambert, S.; Greenlee, M.; Nilsson, S.; Thorsell, A.; Mojena, M.; Tudela, C.; Frisch, K.; Chan, W.; Birzin, E. T.; Rohrer, S. P.; Hammond, M. L. Bioorg. Med. Chem. Lett. 2006, 16, 3896-3901.

(31) For the isolation of guanascatepenes, see: (a) Brady, S. F.; Singh, M. P.; Janso, J. E.; Clardy, J. J. Am. Chem. Soc. 2000, 122, 2116-2117. (b) Brady, S. F.; Bondi, S. M.; Clardy, J. J. Am. Chem. Soc. 2001, 123, 9900-9901. For the isolation of heptemerones, see: (c) Valdivia, C.; Kettering, M.; Anke, H.; Thines, E.; Sterner, O.; Tetrahedron 2005, 61, 9527-9532. (d) Kettering, M.; Valdivia, C.; Sterner, O.; Anke, H.; Thines, E. J. Antibiot. 2005, 58, 390-396.

(32) Rajagopal, D.; Narayanan, R.; Swaminathan, S. J. Chem. Sci. 2001, 113, 197-213.

(33) Sano, K.; Kohari, Y.; Nakano, H.; Seki, C.; Takeshita, M.; Tokiwa, M.; Hirose, Y.; Uwai, K. Synth. Commun. 2016, 46, 46-54.

(34) For the total syntheses of furanether B and (+)-isovelleral, see: (a) Bell, R. P. L.; Sobolev, A.; Wijnberg, J. B. P. A.; de Groot, Ae. J. Org. Chem. 1998, 63, 122-128. (b) Franssen, M. C. R.; Jongejan, H.; Kooijman, H.; Spek, A. L.; Bell, R. P. L.; Wijnberg, J. B. P. A.; de Groot, Ae. Tetrahedron: Asymmetry 1999, 10, 2729-2738. (c) Bell, R. P. L.; Wijnberg, J. B. P. A.; de Groot, Ae. J. Org. 
Chem. 2001, 66, 2350-2357. For the study of the biological activity of both enantiomers of isovelleral showing the superior characteristics of the unnatural (-)-isovelleral enantiomer, see: (d) Jonassohn, M.; Hjertberg, R.; Anke, H.; Dekermendjian, K.; Szallasi, A.; Thines, E.; Witt, R.; Sterner, O. Bioorg. Med. Chem. 1997, 5, 1363-1367.

(35) The reaction conditions for these two steps have not been optimized.

(36) $1^{\text {st }}$ cycle: $98 \%$ yield. $2^{\text {nd }}$ cycle: $89 \%$ yield, $3^{\text {rd }}$ cycle: $65 \%$ yield.

(37) Similar results were observed when using DMF instead of 2-MeTHF. See SI for more details (Table S1).

(38) For example, see: (a) Pericàs, M. A.; Herrerías, C. I.; Solà, L. Adv. Synth. Catal. 2008, 350, 927-932. (b) Kasaplar, P.; Rodríguez-Escrich, C.; Pericàs, M. A. Org. Lett. 2013, 15, 3498-3501. (c) Ayats, C.; Henseler, A. H.; Dibello, E.; Pericàs, M. A. ACS Catal. 2014, 4, 3027-3033. (d) Osorio-Planes, L.; Rodríguez-Escrich, C.; Pericàs, M. A. Chem. Eur. J. 2014, $20,2367-2372$.

\section{TOC Graphic}

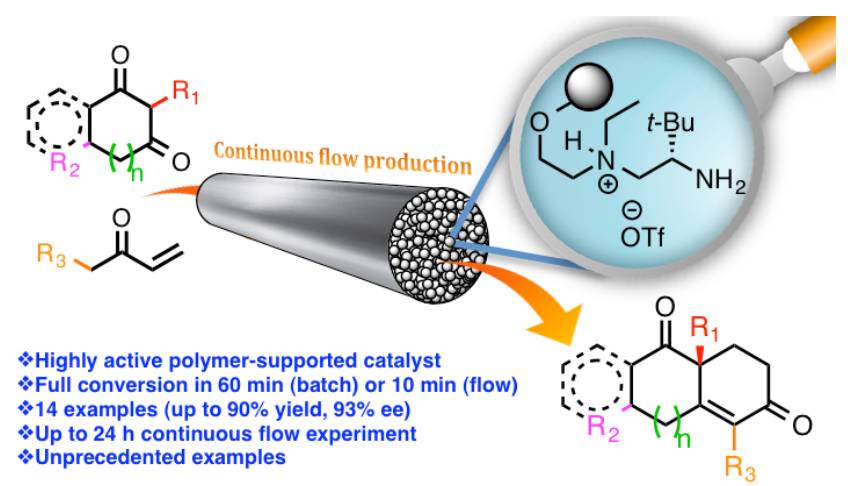

